\title{
Factors Leading to Re-revision Surgery Following the Index Total Hip Arthroplasty Revision: Mid-Term Results
}

\author{
(D) Göksel DİKMEN, id Vahit Emre ÖZDEN, iD Kayahan KARAYTUĞ, id İ. Remzi TÖZÜN \\ Acıbadem Mehmet Ali Aydınlar University, Acıbadem Maslak Hospital, Clinic of Orthopedics and Traumatology, İstanbul, Turkey
}

\section{ABSTRACT}

Objective: The aim of this study was to evaluate the factors that led to re-revision surgeries in patients who underwent revision total hip arthroplasties (THA).

Methods: A total of 352 revision THAs in 274 hips of 252 patients (January 2001-December 2012) were retrospectively analyzed. Patients with a history of a major component revision surgery, replacement of the modular components, debridement and irrigation with liner exchange in the presence of infection and a two-stage revision surgery were included in the study. The mean follow-up period after the revision surgery was 7.5 (range: 2 to 15 ) years.

Results: A re-revision surgery was required in $17.6 \%$ of the index THA revision patients (62 THA re-revisions/352 THA revisions). The mean time between the index revision and re-revision surgeries was 60.4 (range: 0.5 to 348 ) months. The most common reason for the second revision surgery was aseptic loosening (38 THA revisions; 61.2\%), followed by instability (8 THA revisions; 12.9\%) and infection (6 THA revisions; $9.1 \%)$. When the re-revision surgery was taken as end point for assessing the survival rate after the index revision surgery, the cumulative survival rate 10 years after the first revision surgery was found $70.8 \%$. No significant relationship was established between age, gender and the type of fixation and the rate of repeat revisions. However, re-revision rates were significantly higher in acetabular-only component revision cases in comparison to other or both component revisions.

Conclusion: In our revision series, the major factor that necessitated a re-revision following index revision surgery was aseptic loosening, followed by instability.

Keywords: Revision, total hip arthroplasty, survival

\section{Introduction}

Although the functional outcomes following total hip arthroplasty (THA) have significantly improved, the ever increasing number of revision surgeries and implant failures are still major problems (1-3). The greatest expectation of a revision patient is to recover with good functional outcome and without need of a re-revision surgery $(4,5)$. The rate of re-revision surgeries unfortunately shows that this expectation is met at a very low level (4). Considering that the number of revision surgeries will increase in the future, investigating and evaluating the reasons for re-revision surgeries will be of significant importance in order to decrease the costs and to increase patient satisfaction.

The reasons for revision surgeries following primary THA have been exhibited in several registry system and multicenter studies $(1,2,6)$. On the other hand, the reasons for re-revision surgeries in patients who had already undergone a revision surgery have been rarely reported in the literature. Studies that address the outcomes following revision surgery usually evaluate the surgical techniques, classification of the outcomes based on the acetabular or femoral defect and the success and survival rates of the

Address for Correspondence: Göksel DiKMEN, Acıbadem Mehmet Ali Aydınlar University, Acıbadem Maslak Hospital, Clinic of Orthopedics and Traumatology, İstanbul, Turkey

Phone: +90 2123044485 E-mail: goksel.dikmen@acibadem.edu.tr ORCID ID: orcid.org/0000-0001-6891-3488 
featured implants (7-10). The most common reasons to repeat revision surgery following THA revision surgeries are infection, aseptic loosening, the wear on the interface and osteolysis and dislocation secondary to the wear $(1,3,7,11-14)$. Re-revisions are usually performed within the first two years of revision surgery, and infection and technical errors are the major problems in the first years $(6,12,15)$.

Understanding and recognizing the factors that necessitate rerevision surgeries may play a significant role in the success of rerevision surgery. Therefore, in this study, we aimed to investigate the factors, which led to repeat revision surgery following revision THA surgery and to identify the patient-related and implantrelated factors and to evaluate the survival rates following the index revision surgery.

\section{Method}

A total of 352 THA revision surgeries in 274 hips of 252 patients (184 females, 68 males) with varying indications performed between January 2001 and December 2012 were retrospectively analyzed. The mean age of the patients at the time of revision surgery was 59 (range: 22 to 86) years. One hundred fifty one patients were over 65 years of age and 101 were below 65 years of age. Patients with a history of a major (acetabular or femoral) component revision surgery, replacement of the modular components (femoral head-acetabular liner), debridement and irrigation with linear exchange in the presence of infection and a two-stage revision surgery for infection were included in the study. Patients who had undergone closed reduction due to postoperative instability were excluded. The initial diagnosis of the patient that necessitated a revision surgery, the surgical technique employed, the radiological and clinical follow-up after the index revision surgery, and the reasons for the second and third revision surgeries, if any, were retrieved from the FileMaker 10.0 registry system of the senior surgeon (XX) and recorded. The senior surgeon carried out all surgical interventions. The Ethics Committee of Aclbadem University approved this clinical study according to the declaration of Helsinki. Written informed consent was obtained from each participant before commencement of the study.

The THA revisions were classified based on the type of fixation as cemented, cementless, hybrid and reverse hybrid; the component type as acetabular, femoral, acetabular and femoral, and head and linear; and the surface material of the implant as metalpolyethylene, metal-metal, ceramic-polyethylene, zirconiumpolyethylene, and ceramic-ceramic (Table 1). The reasons for rerevision surgery after the index revision surgery were re-evaluated based on the type of fixation, the component type and the surface of the implant used.

The MedCalc v.17.9 software (MedCalc Software bvba, Ostend, Belgium) was used in statistical analyses. In evaluation of the study data, descriptive statistical methods (mean, standard deviation, median, frequency, percentage) were used in addition to the Mann-Whitney U test used in intergroup comparisons of the qualitative data that did not show normal distribution due to the number of cases. The Fisher-Freeman-Halton test was employed in evaluation of the quantitative data. The levels of significance were set at $\mathrm{p}<0.01$ and $\mathrm{p}<0.05$. The revision of any component due to any reason following the index THA revision surgery was considered as the final time point of survival and the survival rates were evaluated with the Kaplan-Meier analysis.

\section{Results}

A re-revision surgery was needed in $17.6 \%$ of the index THA revision patients (62 THA re-revisions / 352 THA revisions). The mean time between the index revision and repeat revision surgeries was 60.4 (range: 0.5 to 348 ) months. The most common reason for the second revision surgery was aseptic loosening (38 THA revisions; 61.2\%). Aseptic loosening was observed after a mean period of 67 (range: 1.2 to 368) months after the index revision surgery. The following reasons for the failure of the first revision surgery were instability (8 THA revisions; $12.9 \%$ ) and infection (6 THA revisions; 9.1\%). Instability and infection were mostly observed in the early term, within the first two years of the revision surgery, after a mean period of 26 (range: 1 to 108) months and 28 (range: 2 to 107) months, respectively. Periprosthetic fracture after the index revision surgery was the last variable among the reasons for re-revision surgery. Of those who underwent a re-revision surgery, 13 (15 hips; 5.47\%) needed a third revision surgery.

No statistically significant difference was detected between the rates of re-revision surgeries among the patients over 65 years of age and under 65 years of age $(\mathrm{p}=0.123)$. Similarly, no significant difference was observed between the rates of re-revision surgeries among patients with cemented and cementless fixation types $(\mathrm{p}=0.851)$. Patients who underwent revision surgeries with isolated acetabular components comprised the group which had the highest rates of repeat revision surgery (28 rTHA/73 rTHA) and the rate of re-revision surgery in this group was significantly higher than those who required the replacement of both components $(\mathrm{p}<0.001)$. The most commonly used femoral component in patients in which isolated femoral revisions and

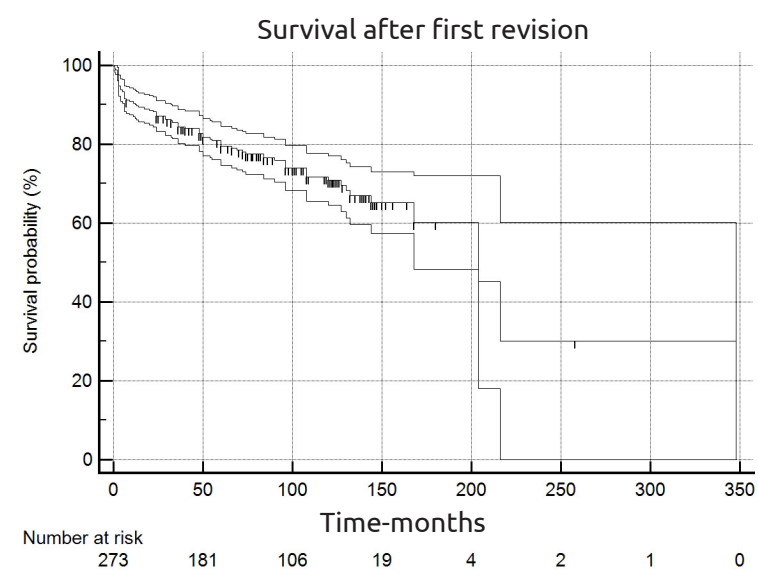

Figure 1. Survival rates of the patients following the index revision surgery 
Table 1. Demographic data of the patients who underwent revision surgery

\begin{tabular}{|c|c|c|c|}
\hline & Total & $\begin{array}{l}\text { Patients Not Undergone Re-Revision } \\
\text { Surgery }\end{array}$ & $\begin{array}{l}\text { Patients Undergone Re-Revision } \\
\text { Surgery }(n=55)\end{array}$ \\
\hline \multicolumn{4}{|l|}{ Gender } \\
\hline Female & $184(73.0 \%)$ & $148(80 \%)$ & $40(20 \%)$ \\
\hline Male & $68(27.0 \%)$ & $53(88.3 \%)$ & $15(16.7 \%)$ \\
\hline \multicolumn{4}{|l|}{ Age } \\
\hline$>65$ years & $151(59.9 \%)$ & $113(75 \%)$ & $38(25 \%)$ \\
\hline$<65$ years & $101(40.1 \%)$ & $84(83.2 \%)$ & $17(16.8 \%)$ \\
\hline \multicolumn{4}{|l|}{ Type of fixation } \\
\hline Cementless & $136(54.0 \%)$ & $103(75 \%)$ & $33(25 \%)$ \\
\hline Cemented & $60(23.8 \%)$ & $47(78 \%)$ & $13(22 \%)$ \\
\hline Hybrid & $32(12.7 \%)$ & $28(87.5 \%)$ & $4(12.5 \%)$ \\
\hline Reverse hybrid & $21(8.3 \%)$ & $17(80.9 \%)$ & $3(19.1 \%)$ \\
\hline Unknown & $2(0.7 \%)$ & 0 & $2(100 \%)$ \\
\hline \multicolumn{4}{|l|}{ Replaced component } \\
\hline Femoral and acetabular & 150 & $128(85.3 \%)$ & $22(14.6 \%)$ \\
\hline Acetabular & 73 & $45(61.6 \%)$ & $28(38 \%)$ \\
\hline Femoral & 21 & $17(85.8 \%)$ & $3(14.2 \%)$ \\
\hline Head and Liner & 5 & 5 & 0 \\
\hline Unknown & 2 & 0 & $2(100 \%)$ \\
\hline \multicolumn{4}{|l|}{ Implant surface } \\
\hline $\begin{array}{l}\text { Cobalt-Chromium (CoCr)- } \\
\text { Polyethylene }\end{array}$ & $117(50 \%)$ & $76(66 \%)$ & $39(33.9 \%)$ \\
\hline Zirconium-Polyethylene (ZoP) & $20(7.9 \%)$ & $18(90 \%)$ & $2(10 \%)$ \\
\hline Oxinium-Polyethylene (OxoP) & $50(19.8 \%)$ & $48(96 \%)$ & $2(4 \%)$ \\
\hline Ceramic-Polyethylene (CoP) & $11(4.9 \%)$ & $11(100 \%)$ & 0 \\
\hline Ceramic-Ceramic (CoC) & $54(21.4 \%)$ & $43(79.6 \%)$ & $11(20 \%)$ \\
\hline Metal-Metal & $3(1.1 \%)$ & $2(67 \%)$ & $1(33 \%)$ \\
\hline
\end{tabular}

synchronous revision of the femoral and acetabular components were performed was the fully porous-coated cementless cylindrical stems, which provided a distal attachment. In terms of the surface bearings of the implants, the metal-polyethylene group was the one that underwent the highest number of rerevision surgeries. The rates of repeat revision surgeries in other surface bearing groups were comparable.

When the second revision surgery was taken as the final time point for assessing the survival rate after the index revision surgery, the cumulative survival rate 10 years after the first revision surgery was found $70.8 \%$ (95\% CI: $65.3 \%$ to $77.8 \%$ ) (Figure 1). The cumulative survival rate after 10 years was $76.5 \%$ (95\% CI: $61.5 \%$ to $75.6 \%$ ) in cases with aseptic loosening, $43 \%$ (95\% CI: $38.5 \%$ to $65.6 \%$ ) in cases with instability, 68\% (95\% CI: $57.5 \%$ to $72.5 \%)$ in cases with infection and $66 \%$ (95\% CI: $53.5 \%$ to $69.6 \%$ ) in cases with polyethylene wear.

\section{Discussion}

The anticipated increase in the number of THA revision surgeries, expected to reach as high as the number of primary revision surgeries, with the increasing number of primary THAs is a major problem for orthopedic surgeons $(1,7,16,17)$. Investigating and understanding the reasons for re-revision surgeries following the index THA revision surgery will increase the rate of success in re-revision surgeries. In our study designed to establish the abovementioned factors, the most common reasons which led to repeat revision surgeries in order of frequency were aseptic loosening, infection and instability, polyethylene wear, and osteolysis and periprosthetic fractures secondary to the wear.

Infection and instability were seen within two years of the index revision surgery, as it was the case in primary THAs, and aseptic loosening was observed after a mean period of five years after the index revision surgery. In concordance with the findings from 
the literature, aseptic loosening and instability were the primary factors that necessitated a re-revision surgery following primary and revision THAs. In our patient series, aseptic loosening was mostly seen in patients who underwent the revision of the acetabular components, a finding in contrast to other studies that reported the highest prevalence of aseptic loosening with femoral components $(11,18,19)$. However, the use of fully porouscoated femoral stems in repeat revision surgeries with femoral components was in concordance with the practices reported in the literature $(11,20)$.

The surgical technique and the type of fixation assessed in our study were not significant factors in necessitating a repeat revision surgery following the revision THA. The need for a repeat revision surgery was significantly higher only in the isolated acetabular component revisions in comparison to other component revisions. There was no statistically significant difference between the rates of repeat revision surgeries among the patients over 65 years of age and under 65 years of age. However, it has been reported that the number of revision THAs increases significantly between 45 and 65 years of age whereas revisions due to dislocations decrease on the contrary (19). Furthermore, obesity has been shown to have a great impact on the success of THA revision surgery in another study (21).

\section{Study Limitations}

The retrospective design of our study, lack of randomization and a control group are some of the limitations of our study. The absence of the demographic data of the patients (BMI, ASA scores) and the classification of the acetabular and femoral defects can be considered as the other limitations. In addition, patients with radiological loosening and/or those scheduled to undergo a second revision were not included in the survival analysis. However, performance of the surgeries by a single senior surgeon with a vast professional experience provides standardization of the surgical technique and clinical follow-up.

\section{Conclusion}

In this study, we evaluated the factors that had an impact on the survival rate following the index rTHA in terms of surgical technique, age and the component type in a mid-term follow-up of the patients in our series. The leading factor which required a re-revision surgery following the index THA revision surgery was aseptic loosening, followed by instability. Cases who underwent isolated acetabular component revision surgery comprised the group with the highest rate of re-revision surgery. The cumulative survival rate 10 years after the first revision surgery was found $70.8 \%$ (95\% CI: $65.3 \%$ to $77.8 \%$ ).

\section{Ethics}

Ethics Committee Approval: ATADEK-2018-4/36

Informed Consent: Retrospective study.

Peer Review: Externally peer-reviewed.

\section{Authorship Contributions}

Concept: G.D., Design: G.D., V.E.O., Data Collection or Processing: I.R.T., Analysis or Interpretation: G.D., V.E.O., K.K., Literature Search: G.D., K.K., Writing: G.D., K.K.

Conflict of Interest: No conflict of interest was declared by the authors.

Financial Disclosure: The authors declared that this study received no financial support.

\section{References}

1. Ulrich SD, Seyler TM, Bennett D, Delanois RE, Saleh KJ, Thongtrangan I, et al. Total hip arthroplasties: what are the reasons for revision? Int Orthop 2008;32:597-604.

2. Söderman P, Malchau H, Herberts P. Outcome after total hip arthroplasty: Part I. General health evaluation in relation to definition of failure in the Swedish National Total Hip Arthroplasty register. Acta Orthop Scand 2000;71:354-9.

3. Berry DJ, Harmsen WS, Cabanela ME, Morrey BF. Twenty-five-year survivorship of two thousand consecutive primary Charnley total hip replacements: factors affecting survivorship of acetabular and femoral components. JBJS 2002;84:171-7.

4. Barrack RL, McClure JT, Burak CF, Clohisy JC, Parvizi J, Hozack W. Revision total hip arthroplasty: the patient's perspective. Clin Orthop Relat Res 2006;453:173-7.

5. Saleh KJ, Celebrezze M, Kassim R, Dykes DC, Gioe TJ, Callaghan JJ, et al. Functional outcome after revision hip arthroplasty: a metaanalysis. Clin Orthop Relat Res 2003;(416):254-64.

6. Losina E, Barrett J, Mahomed NN, Baron JA, Katz JN. Early failures of total hip replacement: effect of surgeon volume. Arthritis Rheum 2004;50:1338-43.

7. Lie S, Havelin L, Furnes O, Engesaeter L, Vollset S. Failure rates for 4762 revision total hip arthroplasties in the Norwegian Arthroplasty Register. J Bone Joint Surg Br 2004;86:504-9.

8. Lachiewicz PF, O'Dell JA. Tantalum components in difficult acetabular revisions have good survival at 5 to 10 years: Longer term followup of a previous report. Clin Orthop Relat Res 2018;476:33642.

9. Gladnick BP, Fehring KA, Odum SM, Christie MJ, DeBoer DK, Fehring TK. Midterm Survivorship After Revision Total Hip Arthroplasty With a Custom Triflange Acetabular Component. J Arthroplasty 2018;33:500-4.

10. Hooten J, Engh C. Failure of structural acetabular allografts in cementless revision hip arthroplasty. J Bone Joint Surg $\mathrm{Br}$ 1994;76:419-22.

11. Springer BD, Fehring TK, Griffin WL, Odum SM, Masonis JL. Why revision total hip arthroplasty fails. Clin Orthop Relat Res 2009;467:166-73.

12. Jafari SM, Coyle C, Mortazavi SJ, Sharkey PF, Parvizi J. Revision hip arthroplasty: infection is the most common cause of failure. Clin Orthop Relat Res 2010;468:2046-51. 
13. Engelbrecht D, Weber F, Sweet M, Jakim I. Long-term results of revision total hip arthroplasty. Bone \& Joint Journal. 1990;72:41-5.

14. Clohisy JC, Calvert G, Tull F, McDonald D, Maloney WJ. Reasons for revision hip surgery: a retrospective review. Clin Orthop Relat Res 2004;188-92.

15. Katz JN, Wright EA, Wright J, Malchau H, Mahomed NN, Stedman M, et al. Twelve-year risk of revision after primary total hip replacement in the US Medicare population. J Bone Joint Surg Am 2012;94:1825-32.

16. Yao JJ, Kremers HM, Abdel MP, Larson DR, Ransom JE, Berry DJ, et al. Long-term Mortality After Revision THA. Clin Orthop Relat Res 2018;476:420-426.

17. Alberton GM, High WA, Morrey BF. Dislocation after revision total hip arthroplasty: an analysis of risk factors and treatment options. JBJS 2002;84:1788-92.
18. Kavanagh BF, Fitzgerald JR. Multiple revisions for failed total hip arthroplasty not associated with infection. J Bone Joint Surg Am $1987 ; 69: 1144-9$

19. Rajaee SS, Campbell JC, Mirocha J, Paiement GD. Increasing Burden of Total Hip Arthroplasty Revisions in Patients Between 45 and 64 Years of Age. J Bone Joint Surg Am 2018;100:449-58.

20. Paprosky WG, Greidanus NV, Antoniou J. Minimum 10-year-results of extensively porous-coated stems in revision hip arthroplasty. Clin Orthop Relat Res 1999;230-42.

21. Kennedy JW, Young D, Meek DR, Patil SR. Obesity is associated with higher complication rates in revision total hip arthroplasty. J Orthop 2018;15:70-2. 